\title{
Penerapan Algoritma Horspool pada Aplikasi Katalog Buku Perpustakaan
}

\author{
Fince Tinus Waruwu' ${ }^{1}$, Rivalri Kristianto Hondro ${ }^{2}$ \\ 1,2 STMIK Budi Darma \\ Jl. Sisingamangaraja No. 338, Medan - Sumatera Utara, (061) 7875998 \\ fincedav@gmail.com, rivalryhondro@gmail.com
}

\begin{abstract}
The library is a place that provides various types of reading books as reference material for students, students, educators and the general public. The library certainly provides various types of books that are different according to their needs. Finding books that are needed in a library with a large number of books certainly takes a long time and energy. In supporting library services and providing convenience for visitors, an application is built that helps visitors find the books they need to not need a long time and effort. In the book catalog application it is necessary to apply a search algorithm (string matching). Search algorithms help enders in finding the books they need. The search algorithm applied to the library book catalog application is the Horspool algorithm. Horspool algorithm is one algorithm that is widely used in the search process. By applying the Horspool algorithm in the library book catalog application can be faster and facilitate the process of finding the title of the book.
\end{abstract}

Keywords: Book Catalog, String Matching, Horspool, Library

Abstrak- Perpustakaan sebuah tempat yang menyediakan berbagai jenis buku baca sebagai bahan referensi bagi siswa, mahasiswa, tenaga pendidik dan masyarakat umum. Perpustakaan tentu menyediakan berbagai jenis buku yang berbeda-beda yang sesuaidengan dibutuhkan. Mengakses buku yang dibutuhkan pada sebuah perpustakaan dengan jumlah koleksi buku yang banyak tentu membutuhkan waktu yang lama dan tenaga. Dalam mendukung pelayanan dan kenyamanan bagi pengunjung maka dibangun sebuah aplikasi yang bisa memudahkan para pengunjung mengakses buku yang dibutuhkannya untuk tidak membutuhkan waktu yang lama dan tenaga. Pada aplikasi katalog buku perlu diterapkan algoritma pencarian (string matching). Algoritma pencarian membantu para pengujung dalam mengakses buku yang dibutuhkan. Algoritma pencarian yang diterapkan pada aplikasi katalog buku perpustakaan adalah algoritma Horspool. Algoritma Horspool salah satu algoritma yang banyak digunakan dalam proses pencarian. Dengan menerapkan algoritma Horspool pada aplikasi katalog buku perpustakaan dapat lebih cepat dan memudahkan dalam proses pencarian judul buku.

Kata Kunci: Katalog Buku, String Matching, Horspool, Perpustakaan

\section{PENDAHULUAN}

Pada erat eknologi yang berkembang saat ini semakin tidak bisa dihindari. Teknologi sudah mulai berperan mengambil alih beberapa macam pekerjaan manusia. Manusia dimanjakan dengan disuguhkan perkembangan jenis teknologi yang canggih untuk membantu menyelesaikan berbagai pekerjaan manusia. Salah satunya dalam mencatat koleksi berbagai jenis buku yang disimpan pada perpustakaan. Perpustakaan sekarang kebanyakan sudah menggukan aplikasi 
yang bisa membantu petugas dan pengunjung dalammengakses berbagai jenis buku koleksi dengan mudah.

Perpustakaan merupakan salah satu fasilitas yang disediakan suatu Lembaga atau instansi seperti sekolah, perguruan tinggi, atau pun daerah. Perpustakaan berfungsi sebagai tempat menyimpan berbagai koleksi buku, pendidikan, penelitian, kultura, informatif dan juga tempat rekreasi. Perpustakaan menyediakan berbagai jenis buku baca yang berfungsi sebagai referensi bagi siswa, mahasiswa dan masyarakat umum. Mengingat jumlah koleksi buku yang banyak maka akan membuat petugas atau pengujung kesulitan dalam melakukan pencarian jenis buku yang dibutuhkan. Dengan demikian maka dibangun sebuah aplikasi katalog buku pada perpustakaan. Dalam proses mencari berbagai jenis koleksi buku perlu menggunakan metode yang disebut dengan pencocokan teks (string matching). Pencocokan teks (string matching) tergantung dari teknik yang diperlukan dalam pencarian teks terhadap dokumen yang dicari. Pencocokan teks(string matching) merupakan faktor utama yang mendukung dalam proses pencarian teks terhadap informasi dokumen yang dibutuhkan. Pencocokan teks merupakan salah satu algoritma yang sering digunakan dalam mempercepat pencarian teks yang diinginkan. Algoritma pencocokan teks sudah sering digunakandalam proses pencocokan teks sebelumnya untuk menemukan kesamaan teks. Algoritma pencocokan teks yang digunakan dalam pencarian persamaan teks yaitu Algoritma Horspool. Algoritma Horspool merupakan proses pencocokan teks. Pencocokan teks akan berjalan secara efesien bila mempunyai tabel untuk menentukan berapa panjang karakter yang digeser seandainya terdeteksi ketidak kesamaan di karakter ke-j dari pattern.

Pada penelitian sebelumnya dikatakan Algoritma Horspool dapat diimplementasikan kedalam aplikasi taksonomi berbasis android dimana algoritma Horspool diterapkan pada kolom pencarian latin maupun pencarian umum [1]. Algoritma Horspool dalam proses mengakses berhasil di implementasikan dan dapat diterapkan denganbaiktan paada error [2]. Algoritma Horspool merupakan modifikasi dari algoritma boyermoore dengan sedikit perkembangan. Tidak seperti algoritma boyermoore, algoritma Horspool cukup menggunakan pergeseran karakter dimana algoritma boyermoore menggunakan dua tabel: pergeseran karakter dan good suffix shif [1]. Berdasarkan uraian latar belakang masalah diatas maka peneliti mengusulkan judul penelitian dengan judul "Penerapan Algoritma Horspool Pada Aplikasi Katalog Buku Perpustakaan"

\section{METODOLOGI PENELITIAN}

\subsection{Kerangka Penelitian}

Kerangka kerja merupakan struktur konseptual dasar yang digunakan untuk memecahkan atau menangani suatu masalah yang kompleks. Berdasarkan pedoman dari langkah kerja inilah penelitian akan dilakukan. 


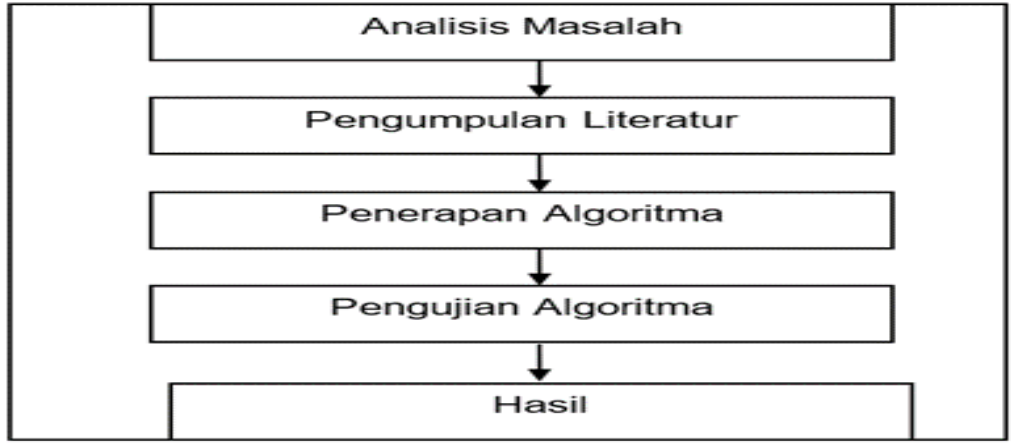

Gambar 1. Kerangka Penelitian

\subsection{Aplikasi}

Aplikasi adalah koleksi window dan objek-objek yang menyediakan fungsi untukaktivitasuser, sepertipemasukan data, proses danpelaporan [3]. Interface: pilihan, jendela, pengaturan jendela dimana seorang pengguna bisa menggunakan langsung dengan aplikasi yang baru dibangun. Media komunikasi dan Bahasa pemrograman yang dibangun dalam membangun aplikasi secara logis. Langkahlangkah yang dilakukan dalam membangun sebuah aplikasi dengan menentukan media komunikasi atau terpisah dari tersendiri.

\subsection{Algoritma}

Algoritma berasal dari kata al-kwarizmi yang terdapat dibuku Abu Ja'far Muhammad Ibnu Musa Al-Kwarizmi seorang ahli matematika dari Persia dengan judul bukunya "AljabarwalMuqabala". Dalam beberapa buku terdapat beberapa defenisi algoritma. Tetapi kalau kita cermati dengan baik, buku-buku tersebut mempunyai tujuan yang sama. Dalam buku ini, defenisi Algoritma merupakan rangkaian langkah-langkah dalam menyelesaikan suatu masalah yang terstruktur dari awal sampai akhir [5]. Terdapat dua istilah yang menjadi ancuan dalam defenisi ini yaitu sistematis dan logis.

\subsection{Horspool}

Algoritma horspool merupakan hampir sama kerjanya dengan algoritma boyermoore dimana melakukan kesamaan antara pattern yang dikasih indeks dengan teks. Algoritma Horspool tidak efisien untuk kata yang pendek. Pada algoritma horspool diberikan nilai pergeseran karakter dari yang sebelah kanan jendela [1]. Pada pengamatan dari yang pertama diberikan nilai pergeseran yang akan diukur pada setiap karakter. Selanjutnya dilakukan persamaan pattern mulai ke dari kanan baru kekiri sampai terdapat hasil kesimpulan sama atau tidak sama. Berikut langkah-langkah yang terdapat pada algoritma Horspool pada tahap pencarian adalah:

1. Dilakukan pencocokan karakter paling kanan pattern terhadap window.

2. Tabel BmBc digunakan untuk melalui karakter ketika ketidaksamaan terjadi.

3. Ketika ada ketidaksamaan, maka karakter yang kanan pada window berfungsi sebagai landasan dalam menentukan jarak shift yang akan dilakukan.

4. Setelah melakukan persamaan (baik hasilnya sama atau tidaksama) dilakukan pergeseran dari kanan pada window. 
5. Prosedur ini dilakukan berulang-ulang sampai window berada pada akhir teks atau ketika pattern sama dengan teks.

\section{PEMBAHASANDAN HASIL}

\subsection{Tahap Praproses}

Melakukan observasi pattern terhadap teks untuk membangun sebuah tabel bad-match yang berisi nilai shift ketika ketidakcocokan antara pattern dan teks

Pattern : JARAN

Tabel 1. BmBc pada praproses

$$
\begin{array}{|l|l|}
\hline \mathrm{J} & 4 \\
\hline \mathrm{A} & 3 \\
\hline \mathrm{R} & 2 \\
\hline \mathrm{A} & 1 \\
\hline * & 5 \\
\hline
\end{array}
$$

\subsection{Tahap Pencarian}

Mendeskripsikan algoritma Hoorspol diberikan teks dan pattern sebagai berikut :

Teks : MEDIA PEMBELAJARAN

Pattern :JARAN

Tabel 2. Inisialisasi awal $\mathrm{BmBc}$

\begin{tabular}{|l|l|l|l|l|l|l|l|l|l|l|l|l|l|l|l|l|l|l|}
\hline $\mathrm{M}$ & 1 & 2 & 3 & 4 & 5 & 6 & 7 & 8 & 9 & 10 & 11 & 12 & 13 & 14 & 15 & 16 & 17 & 18 \\
\hline $\mathrm{T}$ & $\mathrm{M}$ & $\mathrm{E}$ & $\mathrm{D}$ & $\mathrm{I}$ & $\mathrm{A}$ & & $\mathrm{P}$ & $\mathrm{E}$ & $\mathrm{M}$ & $\mathrm{B}$ & $\mathrm{E}$ & $\mathrm{L}$ & $\mathrm{A}$ & $\mathrm{J}$ & $\mathrm{A}$ & $\mathrm{R}$ & $\mathrm{A}$ & $\mathrm{N}$ \\
\hline $\mathrm{P}$ & $\mathrm{J}$ & $\mathrm{A}$ & $\mathrm{R}$ & $\mathrm{A}$ & $\mathrm{N}$ & & & & & & & & & & & & & \\
\hline $\mathrm{I}$ & 0 & 1 & 2 & 3 & 4 & & & & & & & & & & & & & \\
\hline
\end{tabular}

Tabel 3. Pembuatan $B m B c$

\begin{tabular}{|l|l|l|l|l|l|}
\hline $\mathrm{P}$ & $\mathrm{J}$ & $\mathrm{A}$ & $\mathrm{R}$ & $\mathrm{A}$ & $*$ \\
\hline $\mathrm{I}$ & 0 & 1 & 2 & 3 & - \\
\hline $\mathrm{V}$ & 4 & 3 & 2 & 1 & 5 \\
\hline
\end{tabular}

Tabel 4. Iterasi algoritma Horspool pertama

\begin{tabular}{|l|l|l|l|l|l|l|l|l|l|l|l|l|l|l|l|l|l|l|}
\hline $\mathrm{M}$ & 1 & 2 & 3 & 4 & 5 & 6 & 7 & 8 & 9 & 10 & 11 & 12 & 13 & 14 & 15 & 16 & 17 & 18 \\
\hline $\mathrm{T}$ & $\mathrm{M}$ & $\mathrm{E}$ & $\mathrm{D}$ & $\mathrm{I}$ & $\mathrm{A}$ & & $\mathrm{P}$ & $\mathrm{E}$ & $\mathrm{M}$ & $\mathrm{B}$ & $\mathrm{E}$ & $\mathrm{L}$ & $\mathrm{A}$ & $\mathrm{J}$ & $\mathrm{A}$ & $\mathrm{R}$ & $\mathrm{A}$ & $\mathrm{N}$ \\
\hline $\mathrm{P}$ & $\mathrm{J}$ & $\mathrm{A}$ & $\mathrm{R}$ & $\mathrm{A}$ & $\mathrm{N}$ & & & & & & & & & & & & & \\
\hline $\mathrm{I}$ & 0 & 1 & 2 & 3 & 4 & & & & & & & & & & & & & \\
\hline
\end{tabular}

Pada Tabel 4 terdapat ketidakcocokan antara karakter "A" dan "N". Karakter " $A$ " tidak terdapat pada tabel BmBc sehingga digantikan oleh tanda $\left.{ }^{*}\right)$. Tanda $\left({ }^{*}\right)$ bernilai sebesar 5 sehingga dilakukan pergeseran sebanyak 5 kali.

Tabel 5. Iterasi algoritma Horspool kedua

\begin{tabular}{|l|l|l|l|l|l|l|l|l|l|l|l|l|l|l|l|l|l|l|}
\hline $\mathrm{M}$ & 1 & 2 & 3 & 4 & 5 & 6 & 7 & 8 & 9 & 10 & 11 & 12 & 13 & 14 & 15 & 16 & 17 & 18 \\
\hline $\mathrm{T}$ & $\mathrm{M}$ & $\mathrm{E}$ & $\mathrm{D}$ & $\mathrm{I}$ & $\mathrm{A}$ & & $\mathrm{P}$ & $\mathrm{E}$ & $\mathrm{M}$ & $\mathrm{B}$ & $\mathrm{E}$ & $\mathrm{L}$ & $\mathrm{A}$ & $\mathrm{J}$ & $\mathrm{A}$ & $\mathrm{R}$ & $\mathrm{A}$ & $\mathrm{N}$ \\
\hline $\mathrm{P}$ & & & & & & $\mathrm{J}$ & $\mathrm{A}$ & $\mathrm{R}$ & $\mathrm{A}$ & $\mathrm{N}$ & & & & & & & & \\
\hline $\mathrm{I}$ & & & & & & 0 & 1 & 2 & 3 & 4 & & & & & & & & \\
\hline
\end{tabular}

PadaTabel 5 terdapat ketidakcocokan antara karakter "B" dan "N". Karakter "B" tidak terdapat pada tabel BmBc sehingga digantikan oleh tanda 
$(*)$.Tanda $(*)$ bernilai sebesar 5 sehingga dilakukan pergeseran sebanyak 5 kali.

Tabel 6. Iterasi algoritma Horspool ketiga

\begin{tabular}{|l|l|l|l|l|l|l|l|l|l|l|l|l|l|l|l|l|l|l|}
\hline $\mathrm{M}$ & 1 & 2 & 3 & 4 & 5 & 6 & 7 & 8 & 9 & 10 & 11 & 12 & 13 & 14 & 15 & 16 & 17 & 18 \\
\hline $\mathrm{T}$ & $\mathrm{M}$ & $\mathrm{E}$ & $\mathrm{D}$ & $\mathrm{I}$ & $\mathrm{A}$ & & $\mathrm{P}$ & $\mathrm{E}$ & $\mathrm{M}$ & $\mathrm{B}$ & $\mathrm{E}$ & $\mathrm{L}$ & $\mathrm{A}$ & $\mathrm{J}$ & $\mathrm{A}$ & $\mathrm{R}$ & $\mathrm{A}$ & $\mathrm{N}$ \\
\hline $\mathrm{P}$ & & & & & & & & & & & $\mathrm{J}$ & $\mathrm{A}$ & $\mathrm{R}$ & $\mathrm{A}$ & $\mathrm{N}$ & & & \\
\hline $\mathrm{I}$ & & & & & & & & & & & 0 & 1 & 2 & 3 & 4 & & & \\
\hline
\end{tabular}

Pada Tabel 6 terdapat ketidakcocokan antara karakter "A" dan "N". Karakter "A" tidak terdapat pada tabel BmBc sehingga digantikan oleh tanda $\left({ }^{*}\right)$. Tanda $(*)$ bernilai sebesar 5 sehingga dilakukan pergeseran sebanyak 5 kali.

Tabel 7. Iterasi algoritma Horspool keempat

\begin{tabular}{|l|l|l|l|l|l|l|l|l|l|l|l|l|l|l|l|l|l|l|}
\hline $\mathrm{M}$ & 1 & 2 & 3 & 4 & 5 & 6 & 7 & 8 & 9 & 10 & 11 & 12 & 13 & 14 & 15 & 16 & 17 & 18 \\
\hline $\mathrm{T}$ & $\mathrm{M}$ & $\mathrm{E}$ & $\mathrm{D}$ & $\mathrm{I}$ & $\mathrm{A}$ & & $\mathrm{P}$ & $\mathrm{E}$ & $\mathrm{M}$ & $\mathrm{B}$ & $\mathrm{E}$ & $\mathrm{L}$ & $\mathrm{A}$ & $\mathrm{J}$ & $\mathrm{A}$ & $\mathrm{R}$ & $\mathrm{A}$ & $\mathrm{N}$ \\
\hline $\mathrm{P}$ & & & & & & & & & & & & & & $\mathrm{J}$ & $\mathrm{A}$ & $\mathrm{R}$ & $\mathrm{A}$ & $\mathrm{N}$ \\
\hline $\mathrm{I}$ & & & & & & & & & & & & & & 0 & 1 & 2 & 3 & 4 \\
\hline
\end{tabular}

Pada Tabel 7 window telah berada pada akhir teks dan semua pattern cocok dengan teks. Seluruh pencocokan karakter menggunakan algoritma Horspool telah selesai dan berhenti pada iterasi keempat.

\section{KESIMPULAN}

Dengan menerapkan algoritma horspool pada aplikasi katalog buku perpustakaan memberikan kemudahan dan meningkatkan pelayanan perpustakaan terhadap pengunjung dalam mengakses berbagai jenis buku baca yang ada di dalam perpustakaan. Algoritma horspool termasuk algoritma string matching yang dimana dalam proses pencarian string termasuk cepat.

\section{DAFTAR PUSTAKA}

[1] A. Kusnadi, A. K. Wicaksono, F. Teknologi, U. M. Nusantara, dan G. Serpong, "Perbandingan Algoritma Horspool dan Algoritma Zhu-Takaoka dalam Pencarian String Berbasis Desktop," vol. IX, no. 1, hal. 12-16, 2017.

[2] V. Frigustini, A. Erlansari, dan D. Andreswari, "IMPLEMENTASI ALGORITMA HORSPOOL PADA APLIKASI KAMUS BAHASA LINTANG - INDONESIA BERBASIS ANDROID,” vol. 6, no. 1, hal. 88-104, 2018.

[3] R. A.S dan M. Shalahuddin, Rekayasa Perangkat Lunak. Yogyakarta: Modula, 2011.

[4] R. Sarno, Y. Anistyasari, dan R. Fitri, Semantic Search. Yogyakarta: Andi, 2012.

[5] M. K. Drs. Lamhot Sitorus, Algoritma dan Pemrograman, Arie Prame. Yogyakarta: Andi, 2015. 